DOI 10.14746/ppuam.2019.9.04

\author{
Dominika Iwan
}

\title{
Autonomous Vehicles - a New Challenge to Human Rights?
}

\section{Introduction}

Undoubtedly, modern technology has been disrupting many aspects of human life, also in the context of transportation and road vehicles. The transformation taking place in the driving market aims at improving safety, mobility and efficiency of vehicles. From the very beginning, car manufacturers have been developing systems that improve vehicle safety and comfort, in addition to communicate with and assist the driver; such comprehensive systems make the variety of electronic control units remarkable ${ }^{1}$. Advancements have led to cars that can operate without human intervention (hitherto: autonomous vehicles, driverless, selfdriving or robotic cars). Nevertheless, in Arizona on March 18th, 2018 a woman got hit by an Uber autonomous vehicle, because she stepped into the road and fell under the car. The key nuance of this accident was that the car system never took action to prevent the fatality ${ }^{2}$. Consequently, the accident ignited a debate over the legality of driverless cars.

This paper consists of three parts, each of them examining: 1) the definition and components of autonomous vehicles, 2) the benefits of autonomous driving, 3) human rights influenced by introducing driverless cars onto public roads. These considerations lead to the question whether robotic cars are indeed a new challenge to human rights. The question of a driver and his/her liability remains open, but some valuable remarks have already been developed, for example within the European Union framework. ${ }^{3}$

1 E.g.: Electronic Stability Program, advanced driver assistance systems, units ameliorating passengers' comfort, communication systems (vehicle to vehicle, vehicle to infrastructure, vehicle to pedestrian communication systems).

2 S. Levin, J. C. Wong, Self-driving Uber kills Arizona Woman in first Fatal Crash Involving Pedestrian, 19.03.2018, <https://www.theguardian.com/technology/2018/mar/19/uber-self-driving -car-kills-woman-arizona-tempe>.

3 European Parliamentary Research Service, A common EU Approach to Liability Rules and Insurance for Connected and Autonomous Vebicles. European Added Value Assessment Accompanying the 
66 Adam Mickiewicz University Law Review

\section{Terminology}

Nowadays, more and more electronic control units are put into vehicles. All drivers are used to such conveniences as Electronic Stability Program or Advanced Driver Assistance Systems ${ }^{4}$. Artificial intelligence has also been used in vehicle technology, however as drivers give more and more driving tasks to automated systems, the levels of autonomy depend on the balance among the dynamic driving tasks between human and artificial intelligence, from zero to full automation. An autonomous vehicle is defined as a road vehicle able of sensing the environment and control movements without a human driver. It replaces the human driver with artificial intelligence ${ }^{5}$, after hardware sensor data (collected from: cameras, radar and lidar) are sent to the artificial intelligence, which then determines how the vehicle should behave. Obviously, there is no one autonomy of vehicle in question, but levels of autonomy depend on tasks given to the computer algorithm to decide.

In literature, there are five levels of autonomous driving distinguished, based on three factors: 1) steering, acceleration and deceleration, 2) monitoring driving environment, and 3) fall-back performance of dynamic driving tasks ${ }^{6}$. The highest levels - three to five - have already been considered as autonomous, while the fifth level is fully autonomous, since the car performs all these tasks without any human intervention. One of the examples of the legal regulation of the employment of a vehicle's autonomous functions is the European Union Regulation 2015/758 of the European Parliament and of the Council concerning type-approval requirements for the deployment of the eCall invehicle system based on the 112 service and amending Directive 2007/46/EC ${ }^{7}$. Starting from the 1st of April 2018, there is a compulsory calling emergency aid system (working independently) in case of a car crash in all newly produced cars imported to each European Union Member State ${ }^{8}$.

European Parliament's Legislative Own-Initiative Report. Rapporteur: Mady Delvaux), "European Added Value Unit”, PE 615/635, February 2018.

4 <https://www.euroncap.com/en/press-media/press-releases/testingautomation/>.

5 T. Tettamanti, I. Varga, Z. Szalay, Impacts of Autonomous Cars from a Traffic Engineering Perspective, "Periodica Polytechnica Transportation Engineering" 2016, p. 244-250.

$6<$ http://www.europarl.europa.eu/news/en/headlines/economy/20190110STO23102/self-driving-cars-in-the-eu-from-science-fiction-to-reality>; Communication from the Commission to the European Parliament, the Council, the European Economic and Social Committee, the Committee of the Regions: On the road to automated mobility: An EU strategy for mobility of the future, 17.05.2018, Brussels, COM 2018, 283, p.3.

7 Regulation EU 2015/758 of the European Parliament and of the Council of 29 April 2015 concerning type-approval requirements for the deployment of the eCall in-vehicle system based on the 112 service and amending Directive 2007/46/EC, 19.05.2015, Official Journal of the European Union L 123/77.

8 Similar solution - ERA-GLONASS - has been developed in Russia based on the European standard eCall system. 
The immanent component of a robotic car is artificial intelligence. This is an area of computer science responsible for the creation of machines which work and react like humans (so called: intelligent machines) ${ }^{9}$. Artificial intelligence is a highly technical and specialized branch of computer science, within which computers are programmed for certain features, such as: recognition, reasoning, problem solving, perception, learning, planning as well as the ability to manipulate and move objects ${ }^{10}$. Two types of this computer science are distinguished: weak and strong artificial intelligence ${ }^{11}$. The weak one (also known as narrow artificial intelligence) can be responsible for facial recognition or driving a car, while the strong artificial intelligence (also called: general) is a long-term goal of research aiming at performing nearly all cognitive tasks that humans can perform $^{12}$. In this paper, only the narrow artificial intelligence is concerned. Still, the strong artificial intelligence impacts the progress of the weak one.

The main problem resulting from artificial intelligence is the unpredictability of its developments, since computer science and robotics are an ongoing research, but no specific limits are put on this research so far $^{13}$. Nevertheless, while creating machines, one should bear in mind the basic laws of robotics (proposed by American writer and professor of biochemistry - Isaac Asimov): it is primary that a robot may not injure a human being and that a robot must obey human orders ${ }^{14}$. Nonetheless, Asimov's Laws have already been criticised by some scientists, as being too restrictive and contextual ${ }^{15}$. Instead, there are suggestions that 'robots should be empowered to maximise the possible ways they can act ${ }^{16}$ in order to find the best solution for a human ${ }^{17}$. Notwithstanding, more attention should be paid to the ethics of artificial intelligence research in order to ensure that not only the result is important, but also the way artificial intelligence achieves its goals ${ }^{18}$. Very interesting developments in this field have been achieved in the European Union system. The European Commission has appointed a new High-Level Expert Group on Artificial Intelligence to support the implementation of European Union Strategy

\footnotetext{
$9<$ https://www.techopedia.com/definition/190/artificial-intelligence-ai >.

10 Ibidem.

11 <https://futureoflife.org/background/benefits-risks-of-artificial-intelligence/>.

12 Ibidem.
}

13 The only limit seems to be human imagination. Artificial intelligence is even used in creating autonomous weapon systems, it is weapon systems that can act without human intervention.

14 I. Asimov, I Robot: Runaround, New York, 1942.

15 Ch. Salge, Asimor's Laws Won't Stop Robots Harming Humans so We've Developed a Better Solution, "The Conversation", 14.02.2017. <http://theconversation.com/asimovs-laws-wont-stoprobots-harming-humans-so-weve-developed-a-better-solution-80569>.

16 Ibidem.

17 Ch. Salge, D. Polani, Empowerment As Replacement for the Three Laws of Robotics, "Frontiers" 29 June 2017.

18 N. Bostrom, E. Yudkowsky, The Ethics of Artificial Intelligence, in: Cambridge Handbook of Artificial Intelligence, eds. W. Ramsey, K. Frankish, Cambridge 2011. 
on artificial intelligence ${ }^{19}$. The High-Level Expert Group on Artificial Intelligence has prepared a Draft Ethics Guidelines for Trustworthy $\mathrm{AI}^{20}$, in which it considered the issues of: fairness, safety, the future of work, democracy and transparency, but also the impact of technological developments in artificial intelligence for fundamental rights (as prescribed in the Charter of Fundamental Rights of the European Union ${ }^{21}$ ). The following fundamental rights have been taken into consideration: non-discrimination, privacy, personal data protection and consumer protection, which will be discussed below.

Another term inextricably linked to autonomous vehicles is the driver. According to the Oxford Dictionary the definition seems very simple, as a driver is 'a person who drives a vehicle'22. However, when it comes to autonomous vehicles, may a driver be a person who finds themselves in a car (also a child or person with disabilities) or the artificial intelligence itself, thus deciding on driving tasks of a car? This is to be explained in the forthcoming years when autonomous car research develops and attracts States to the level of introducing them onto public roads.

\section{The Benefits of Autonomous Driving}

There are plenty of advantages of introducing autonomous vehicles onto public roads. As they rely less on humans, human-related errors in transportation, such as inattentiveness or intoxication, can be eliminated ${ }^{23}$. Robots are always focused on driving tasks and never get drunk, drowsy or distracted by external factors ${ }^{24}$. Robotic vehicles also provide a great economic, ecological and social benefit ${ }^{25}$. A lot of organizational problems caused by strict regulation for driving and rest hours can be eliminated. Furthermore, driverless cars can ensure optimal headway control and minimize the number of accidents. Due to

19 Communication from the Commission to the European Parliament, the European Council, the Council, the European Economic and Social Committee and the Committee of the Regions: Artificial Intelligence for Europe, 25.04.2018, Brussels, COM, 2018, 237 final.

20 European Commission, High-Level Expert Group on Artificial Intelligence: Draft Ethics Guidelines for Trustworthy AI, 18.12.2018.

21 Charter of Fundamental Rights of the European Union, "Official Journal of the European Union", 2012/C 326/02.

$22<$ https://en.oxforddictionaries.com/definition/driver $>$.

23 R. Sykora, The Future of Autonomous Vehicle Technology as a Public Safety Tool, "Minnesota Journal of Law, Science and Technology" 2015, vol. 16, no. 811; P. Koopman, Autonomous Vehicles Safety: In Interdisciplinary Challenge, "IEEE Intelligent Transportation Systems Magazine" 2017, vol. 9, no. 1, pp. 90-96. See also: European Commission, Report from the Commission to the European Parliament and the Council: Saving Lives: Boosting Car Safety in the EU, 12.12.2016, Brussels, COM, 2016, 787 final.

24 K. Naughton, Just How Safe Is Driverless Car Technology, Really?, "Bloomberg”, 27 March 2018.

25 L. Determann, B. Perens, Open Cars, "Berkeley Technology Law Journal” 2017, vol. 32, no. 915, pp. 915-933. 
optimal work regulation, they can also reduce environmental impact and improve road traffic parameters (i.e. travel time, traffic flow capacity).

Driverless cars can touch upon the increasing demand of mobility for these people who are not able to drive themselves, since such technology offers a very wide mobility opportunity $^{26}$ (for such persons as the elderly or with disabilities). Such developments can address the issue of disability or age discrimination. Following the European Commission's Communication on the road to automated mobility ${ }^{27}$, mobility of people and goods is considered as a priority and an increasing demand for people. In the aftermath of such remarks, European Parliament's Committee for Transport and Tourism proposed a Draft Report on autonomous driving in European transport ${ }^{28}$. The Committee takes it for granted that autonomy in widely perceived transport will appear by $2030^{29}$. Therefore, according to the Draft Report, it is crucial to consider data protection and data access, as well as cyber security in the context of autonomous driving. The Draft Report stresses fundamental blocks of autonomous driving: the vehicle and route data. The massive increase of data produced, gathered, and transmitted from the vehicle will result in the need to use non-personal anonymised data ${ }^{30}$. This is the reason why the international, European Union and national approach to autonomous driving should be based on the principle of an openness and neutrality of technology. The Committee also points out the need to develop key autonomous technologies (namely simulations of the human brain when driving) and employment disturbance awareness resulting from introducing daily autonomous driving ${ }^{31}$. All these issues are analysed in detail below.

\section{Legal Disturbances}

\section{Safety}

Autonomous driving poses a great challenge to public safety requirements, because some sufficient level of safety has to have actually been achieved before deploying such vehicles into the public roads. "Safe" means at least correctly handling vehicle-level be-

26 Communication from the Commission to the European Parliament, the Council, the European Economic and Social Committee, the Committee of the Regions: On the road to automated mobility: An EU strategy for mobility of the future, 17.05.2018, Brussels, COM, 2018, 283 final.

27 Ibidem.

28 Draft Report of the Committee on Transport and Tourism of the European Parliament on autonomous driving in European transport, 20.07.2018, 2018/2089 INI.

29 Not only autonomous cars, but also autonomous rail or air transport.

30 Draft Report of the Committee on Transport and Tourism of the European Parliament on autonomous driving in European transport, 20.07.2018, 2018/2089 INI.

31 Ibidem. 
haviours, including obeying traffic laws ${ }^{32}$, which can differ depending upon location. The sufficient safety level shall also require dealing with non-routine road accidents, to which artificial intelligence actually responses. Driverless vehicles will be programmed to act in a certain way, but the question arises in the situation when, all of the sudden, the circumstances are being changed. Then, for example, the problem with an unexpected situation or extreme weather conditions would let car sensors transmit wrong data to artificial intelligence, thus making it unable to decide correctly upon the car's behaviour. It is therefore mainly not the problem of unpredictable decision of the computer algorithm itself, but the improvements in sensors that collect data and then transfer it to the algorithm. Hence, it is argued that for the time being fully autonomous vehicles cannot be introduced onto public roads, because the requirement of notification of not being able to drive in such conditions is necessary and the control over the vehicle should fall back to the driver. Decisions made by artificial intelligence can be unpredictable while artificial intelligence is programmed to perform tasks beneficially for humans, however, through developing a destructive method for achieving its goals. An autonomous vehicle can be programmed in a way to obey human orders, for example by taking a person to the chosen place as quickly as possible, however it may not only violate driving rules, but also cause an accident.

Nevertheless, the European Commission has already proposed the intelligent speed adaption system ${ }^{33}$ in order to achieve the goals from the Directive of the European Parliament and of the Council on the framework for the deployment of Intelligent Transport Systems in the field of transport of $2010^{34}$. Intelligent Speed Adaption (ISA) is a collective term for various systems that support a driver's compliance with the speed limit, thus preventing a violation of speed limits while driving ${ }^{35}$. One of the examples of the intelligent speed adaption system is the warning that the speed limit is being exceeded (but the decision remains with the driver) ${ }^{36}$. Other categories interfere with car infrastructure by increasing the pressure on the accelerator pedal or - the most interruptive - by limiting the speed automatically (called 'closed ISA') ${ }^{37}$. Such systems have

32 P. Koopman, Autonomous Vehicles Safety..., p. 91.

33 <https://ec.europa.eu/transport/road_safety/specialist/knowledge/speed/new_technologies_ new_opportunities/intelligent_speed_adaptation_isa_en >.

34 Directive 92/6/EEC of the Council on the installation and use of speed limitation devices for certain categories of motor vehicles in the Community, 10.02.1992, "Official Journal of the European Communities", L 57/27; Directive 2010/40/EU of the European Parliament and of the Council, on the framework for the deployment of Intelligent Transport Systems in the field of transport and for interfaces with other modes of transport, 07.07.2010, "Official Journal of the European Union", L 207.

35 A. M. Rook, J. H. Hogema, A. R. A. van der Horst, Intelligent Speed Adaption: Acceptance and Driver Behaviour on Rural Roads, "Proceedings ICTCT Workshop Tartu", Soesterberg, 2004.

36 J. P. Cauzard ed., SARTRE Report: European drivers and road risks, "Arcueil Cedex" 2004, p. 179.

37 Ibidem. 
already been adapted into certain categories of vehicles within the European Union framework $^{38}$. The experiments held inter alia in Sweden and Great Britain showed that individual incorporation of Intelligent Speed Adaption can result in lesser attentiveness of drivers on the road conditions or frustration caused primarily by the closed ISA ${ }^{39}$. However, the primary benefits resulting from ISA's acceptance are tremendous in the context of safety.

\section{Cybersecurity}

The security system of an autonomous vehicle and its stored data might be vulnerable to hacking and cyber manipulation, as autonomous vehicles are connected to other vehicles or an infrastructure to share or receive data. They are also morally and ethically questionable, when it comes to the absence of a human driver who makes moral decisions in extreme and difficult situations (e.g. the decision to hit a certain object or person). Questions of cybersecurity focus on two main problems: remote taking control over the vehicle and data protection. The first issue relates to specific control upon transmitted data and the process of making decisions by artificial intelligence. This is to be specified in the coming years by researchers responsible for the development of this industry sector as driverless vehicles beyond doubt shall be hacking resistant ${ }^{40}$. In the Draft Recommendation on Cyber Security of the Task Force on Cyber Security and Over-theair Issues prepared by United Nations Economic Commission for Europe (UNECE), over thirty categories of cyber-threats and corresponding mitigations have been distinguished, among them threats regarding back-end servers, as well as threats to vehicles regarding: their communication channels, update procedures, unintended human actions, and external connectivity ${ }^{41}$. Nonetheless, it lists only the examples of cyber-threats.

\section{Privacy}

Subsequently, autonomous vehicles correspond with the right to private life as expressed inter alia in the Art. 8 of the European Convention on Human Rights and Fundamental Freedoms of $1950^{42}$, due to which everyone has the right to respect his private and family

38 Directive 2002/85/EC of the European Parliament and of the Council amending Council Directive 92/6/EEC on the installation and use of speed limitation devices for certain categories of motor vehicles in the Community, 05.11.2002, "Official Journal of the European Communities", L 327.

39 V. Beyst, Project for Research on Speed Adaption Policies on European Roads Final report on Stakeholders Analysis, 2006, <https://ec.europa.eu/transport/road_safety/sites/roadsafety/files/pdf/ projects_sources/prosper_d2-4.pdf>.

40 United Nations Task Force on Cyber Security and Ober-the-Air issues, Draft Recommendation on Cyber Security of the Task Force on Cyber Security and Over-the-air issues of UNECE WP.29 GRVA.

41 Ibidem, pp. 25-39.

42 European Convention on Human Rights and Fundamental Freedoms, European Treaty Series 5. 
life. According to Dorothy J. Glancy, privacy can be affected by autonomous vehicles in at least three ways, all of which are rooted in the dignity of a person ${ }^{43}$ : personal privacy, information privacy, and surveillance.

Firstly, autonomous vehicles would take control over the way people move from place to place and over the data shared ${ }^{44}$. Personal autonomy therefore refers to the decision whether to choose a driverless vehicle or not. It is interconnected with people's selfdetermination and the ability to make independent decisions about themselves ${ }^{45}$. But more importantly, the use of autonomous vehicles will make it harder to control the information on a person's real and forthcoming location, time of departure, the way the person moves from place to place. The question arises as to whether the autonomy of a vehicle makes the autonomy of a person less important, as one has to bear in mind that relationship between a car and a person is not of a binary character. Autonomy refers to independence of decisions, therefore driverless cars are only an example of the delegation of some choices to the vehicle, not precluding personal autonomy. A vehicle can only control its speed or the way it moves from place to place, but most vital decisions remain with in a human's hands. There are two aspects of autonomy, namely the right to make a decision and the freedom from external interferences ${ }^{46}$, whereas the negative aspect of autonomy -freedom from external interferences - is referred to as 'the right to be let alone', which means that the law shall secure each individual's determination of the scope of data communicated to and shared with others ${ }^{47}$. There is little to say as for the example to location-oriented data whether this information shall be shared on commercial basis (to propose adverts). Information privacy, as the second aspect of privacy, collects a person's habits and the most frequent behaviours, thus, anonymity is crucial for the right to be let alone. Last but not least, surveillance privacy which puts limits to the possibility of being monitored by others, will result in some benefits, especially in the case of an accident (the data on speed, location, passengers and driver behaviour would be helpful in determining the potential responsibility and the insurance claim amount). However, such activities shall also be legally restricted and constantly verified. Such safeguards have already been developed within the European Union by adopting the General Data Protection Regulation of 2016, which entered into force in April 2018 ${ }^{48}$.

43 D. J. Glancy, Privacy in Autonomous Vehicles, "Santa Clara Law Review" 2012, vol. 52, no. 1171, p. 1187.

44 Ibidem, p. 1188.

45 Ibidem.

46 S. D. Warren, L. D. Brandeis, The Right to Privacy, "Harvard Law Review”, 1890, vol. 4, no. 5, pp. 193-220.

47 Ibidem, pp. 198.

48 Regulation 2016/679 of the European Parliament and of the Council on the protection of natural persons with regard to the processing of personal data and on the free movement of such data, and repealing Directive 95/46/EC, 27.04.2016, “Official Journal of the European Union”, L 119. 


\section{Conclusion}

To sum up, the benefits from introducing autonomous driving into public roads cannot be overestimated, since driverless vehicles support non-discrimination and the mobility of a person. This can also help in reducing global climate change, as the driving industry constitutes one of the main factors worsening environmental protection. Nowadays the right to environment and human rights are becoming more and more interlinked. Even so, while stepping forward to autonomous driving, one shall bear in mind the necessity of being prepared for the unexpected; meaning that cars can, in certain circumstances, be intelligent enough to decide instead of a human driver. Legislators and the automotive industry must not lose sight of the wider challenges which autonomous cars entail.

Legal issues, including, firstly, human rights, then ethics secondly, must be handled as problem to be solved rather than an obstacle to get around. It is commonly known that laws usually do not respond quickly to technological developments, however, once the legal aspect remains ambiguous, it imposes a great challenge for lawmakers and manufacturers to not only develop technology to acceptable levels, but to gain the market's acceptance of using such technology. New technologies disrupt with human existence and the existence of the general society and, accordingly, the whole research devoted to robotic cars shall put the human and their rights in the centre of all new developments.

\section{Literature}

Asimov I., I Robot: Runaround, New York, 1942.

Beyst V., Project for Research on Speed Adaption Policies on European Roads Final report on Stakeholders Analysis, 2006, <https://ec.europa.eu/transport/road_safety/sites/roadsafety/files/pdf/projects_sources/prosper_d2-4.pdf>.

Bostrom N., Yudkowsky E., The Ethics of Artificial Intelligence, in: Cambridge Handbook of Artificial Intelligence, eds. W. Ramsey, K. Frankish, Cambridge 2011.

Cauzard J. P. ed., SARTRE Report: European drivers and road risks, "Arcueil Cedex" 2004, p. 179.

Determann L., Perens B., Open Cars, "Berkeley Technology Law Journal” 2017, vol. 32, no. 915 .

Glancy D. J., Privacy in Autonomous Vebicles, "Santa Clara Law Review" 2012, vol. 52, no. 1171, p. 1187.

Levin S., Wong J. C., Self-driving Uber kills Arizona Woman in first Fatal Crash Involving Pedestrian, 19.03.2018, <https://www.theguardian.com/technology/2018/mar/19/ uber-self-driving-car-kills-woman-arizona-tempe>.

Naughton K., Just How Safe Is Driverless Car Technology, Really?, "Bloomberg”, 27 March 2018. 
Rook A. M., Hogema J. H., van der Horst A. R. A., Intelligent Speed Adaption: Acceptance and Driver Behaviour on Rural Roads, "Proceedings ICTCT Workshop Tartu", Soesterberg, 2004.

Salge Ch., Asimov's Laws Won't Stop Robots Harming Humans so We've Developed a Better Solution, "The Conversation”, 14.02.2017. < http://theconversation.com/asimovs-lawswont-stop-robots-harming-humans-so-weve-developed-a-better-solution-80569>.

Salge Ch., Polani D., Empowerment As Replacement for the Three Laws of Robotics, "Frontiers" 29 June 2017.

Sykora R., The Future of Autonomous Vebicle Technology as a Public Safety Tool, "Minnesota Journal of Law, Science and Technology" 2015, vol. 16, no. 811; P. Koopman, Autonomous Vehicles Safety: In Interdisciplinary Challenge, "IEEE Intelligent Transportation Systems Magazine” 2017, vol. 9, no. 1, pp. 90-96.

Tettamanti T., Varga I., Szalay Z., Impacts of Autonomous Cars from a Traffic Engineering Perspective, "Periodica Polytechnica Transportation Engineering” 2016, p. 244-250.

Warren S. D., Brandeis L. D., The Right to Privacy, "Harvard Law Review”, 1890, vol. 4, no. 5

Charter of Fundamental Rights of the European Union, "Official Journal of the European Union”, 2012/C 326/02.

Communication from the Commission to the European Parliament, the Council, the European Economic and Social Committee, the Committee of the Regions: On the road to automated mobility: An EU strategy for mobility of the future, 17.05.2018, Brussels, COM 2018, 283, p. 3.

Communication from the Commission to the European Parliament, the European Council, the Council, the European Economic and Social Committee and the Committee of the Regions: Artificial Intelligence for Europe, 25.04.2018, Brussels, COM, 2018, 237 final.

Communication from the Commission to the European Parliament, the Council, the European Economic and Social Committee, the Committee of the Regions: On the road to automated mobility: An EU strategy for mobility of the future, 17.05.2018, Brussels, COM, 2018, 283 final.

Directive 2002/85/EC of the European Parliament and of the Council amending Council Directive 92/6/EEC on the installation and use of speed limitation devices for certain categories of motor vehicles in the Community, 05.11.2002, "Official Journal of the European Communities", L 327.

Directive 92/6/EEC of the Council on the installation and use of speed limitation devices for certain categories of motor vebicles in the Community, 10.02.1992, "Official Journal of the European Communities", L 57/27; Directive 2010/40/EU of the European Parliament and of the Council, on the framework for the deployment of Intelligent Transport Systems in the field of transport and for interfaces with other modes of transport, 07.07.2010, "Official Journal of the European Union”, L 207. 
Draft Report of the Committee on Transport and Tourism of the European Parliament on autonomous driving in European transport, 20.07.2018, 2018/2089 INI.

Draft Report of the Committee on Transport and Tourism of the European Parliament on autonomous driving in European transport, 20.07.2018, 2018/2089 INI.

European Commission, High-Level Expert Group on Artificial Intelligence: Draft Ethics Guidelines for Trustworthy AI, 18.12.2018.

European Convention on Human Rights and Fundamental Freedoms, European Treaty Series 5 .

European Parliamentary Research Service, A common EU Approach to Liability Rules and Insurance for Connected and Autonomous Vehicles. European Added Value Assessment Accompanying the European Parliament's Legislative Own-Initiative Report. Rapporteur: Mady Delvaux), "European Added Value Unit”, PE 615/635, February 2018.

Regulation 2016/679 of the European Parliament and of the Council on the protection of natural persons with regard to the processing of personal data and on the free movement of such data, and repealing Directive 95/46/EC, 27.04.2016, "Official Journal of the European Union”, L 119.

Regulation EU 2015/758 of the European Parliament and of the Council of 29 April 2015 concerning type-approval requirements for the deployment of the eCall in-vehicle system based on the 112 service and amending Directive 2007/46/EC, 19.05.2015, Official Journal of the European Union L 123/77.

United Nations Task Force on Cyber Security and Ober-the-Air issues, Draft Recommendation on Cyber Security of the Task Force on Cyber Security and Over-the-air issues of UNECE WP.29 GRVA.

<http://www.europarl.europa.eu/news/en/headlines/economy/20190110STO23102/ self-driving-cars-in-the-eu-from-science-fiction-to-reality>.

$<$ https://ec.europa.eu/transport/road_safety/specialist/knowledge/speed/new_ technologies_new_opportunities/intelligent_speed_adaptation_isa_en>.

$<$ https://en.oxforddictionaries.com/definition/driver>.

$<$ https://www.euroncap.com/en/press-media/press-releases/testingautomation/>.

$<$ https://www.techopedia.com/definition/190/artificial-intelligence-ai >. 
76 | Adam Mickiewicz University Law Review

SUMMARY

\section{Autonomous Vehicles - a New Challenge to Human Rights?}

New technologies, as autonomous vehicles are, disrupt the way people exist, and consequently with human rights. Research devoted to artificial intelligence and robotics moves freely and the destination, for the time being, is unknown. This is the reason why special attention should be paid to the ethics of these branches of computer science in order to prevent the creation of a crisis point, when human beings are no longer necessary.. The aim of this paper is to examine whether such development is a new challenge to human rights law and what happens when an autonomous vehicle drives an autonomous human being. The paper also mentions the desirable level of human control over the machine so that human dignity, from which human rights originate, is preserved.

Keywords: autonomous vehicles, artificial intelligence, human rights, privacy, cybersecurity

Dominika Iwan: University of Silesia, Faculty of Law and Administration, Bankowa 11b Street, 40-007 Katowice, Republic of Poland, e-mail: dominikaiwan1@gmail.com. 